\title{
Limitations on the use of verb information during sentence comprehension
}

\author{
SHELIA M. KENNISON \\ University of Massachusetts, Amherst, Massachusetts
}

\begin{abstract}
An eye tracking experiment was conducted in order to investigate the role of verb information in resolving structural ambiguity during sentence comprehension. Reading time was measured on sentences containing temporarily ambiguous noun phrases (e.g., "The athlete revealed the problem") that were continued as tensed sentence (S) complements or noun phrase (NP) complements. Ambiguous noun phrases were preceded either by verbs occurring most frequently with NP complements (NPbiased) or verbs occurring most frequently with $\mathrm{S}$ complements (S-biased). Reading time was also measured on sentences containing unambiguous S complements preceded by either NP-biased or S-biased verbs. The results showed that contrary to predictions made by verb guidance theories (e.g., constraint satisfaction; MacDonald, Pearlmutter, \& Seidenberg, 1994a, 1994b; Trueswell \& Tanenhaus, 1994), for both NP- and S-biased verb conditions, sentences containing temporarily ambiguous noun phrase complements were read most quickly, and sentences containing temporarily ambiguous $\mathrm{S}$ complements were read more slowly than those containing unambiguous $\mathrm{S}$ complements.
\end{abstract}

Comprehenders routinely encounter phrases that can be interpreted in more than one way. One of the most wellresearched examples of structural ambiguity is the noun phrase (NP)/ tensed sentence (S) complement ambiguity. Consider the sentence fragment in 1. The NP the answer can be interpreted either as an NP complement of the verb knew, as in 1a, or as the subject NP in an S complement, as in $1 b$.

(1) The student knew the answer....
a. by heart.
NP Complement Continuation
b. was correct
S Complement Continuation

Since the early 1980s, researchers have investigated the possibility that verb information can be used to guide the analysis of subsequent words and phrases (Clifton, Frazier, \& Connine, 1984; Ford, Bresnan, \& Kaplan, 1982; Holmes, Kennedy, \& Murray, 1987; Holmes, Stowe, \& Cupples, 1989; Kennedy, Murray, Jennings, \& Reid, 1989; Mitchell, 1987, 1989; Mitchell \& Holmes, 1985; Tanenhaus \& Carlson, 1989). The use of verb information during structural ambiguity resolution is central to a number of theories of sentence processing (see MacDonald, Pearlmutter, \& Seidenberg, 1994a, for a review). One of the most influential proposals in recent years has been the constraint satisfaction approach (MacDonald, 1994;

This research was conducted in partial fulfillment of a Ph.D. dissertation at the University of Massachusetts and financially supported by Grants HD-07327 and HD-18708 awarded to the University of Massachusetts at Amherst and Grant MH-19554 awarded to the University of Illinois at Urbana-Champaign. Correspondence should be addressed to S. M. Kennison, Department of Psychology, Oklahoma State University, 215 N. Murray, Stillwater, OK 74078-3064 (e-mail: kenniso@ okstate.edu).
MacDonald et al, 1994a, 1994b; Trueswell \& Tanenhaus, 1994). This approach claims that the process of sentence comprehension is one during which comprehenders are influenced by multiple constraints within the sentence and discourse contexts. Verb information is viewed as one of many possible constraints and can be used by comprehenders during the initial stage of structural ambiguity resolution.

An influential model that claims that verb information is not used during the earliest stage of ambiguity resolution is the garden path model of sentence processing. Proponents of this view believe that comprehenders initially utilize information about the major syntactic category of the incoming word (e.g., noun, verb, etc.) and construct the first analysis available, which is the simplest analysis, given the syntactic complexity of alternative interpretations in terms of the number of new syntactic nodes to be added to the ongoing structure (Frazier, 1978; Frazier \& Fodor, 1978; Frazier \& Rayner, 1982). The most controversial aspect of this proposal is that comprehenders are believed to construct the syntactically least complex alternative, despite the fact that in some sentences a syntactically more complex analysis may be more probable based on information other than the major syntactic category of the incoming word, such as information about the preferred usage of a preceding verb.

The present experiment was conducted to investigate the extent to which readers use verb information to resolve temporarily ambiguous NPs, specifically how readers used verb information during the processing of sentences containing ambiguous NPs continued as NP or S complements as well as sentences containing unambiguous $\mathrm{S}$ complements (complements containing the complementizer that). These three types of complements were preceded either by verbs that are generally used most fre- 
Table 1

Sample Stimuli Used in the Experiment

Sample Stimuli Used in the Experiment
Sentence Complement Continuations
NP-Biased Verb
The athlete $\mid$ revealed $\mid$ (that) $\mid$ his problem $\mid$ (with prescription drugs) $\mid$ worried his parents
$\mid$ nearly every single moment.
S-Biased Verb
The athlete $\mid$ admitted $\mid$ (that) $\mid$ his problem $\mid$ (with prescription drugs) $\mid$ worried his parents
| nearly every single moment.
NP-Biased Verb
The athlete | revealed | his problem $\mid$ (with prescription drugs) $\mid$ because his parents
| worried every single moment.
S-Biased Verb
The athlete $\mid$ admitted | his problem $\mid$ (with prescription drugs) $\mid$ because his parents
|worried every single moment.
Note-Words in parentheses occurred in a subset of conditions. The "|" symbols indicate
analysis regions.

quently with NP complements (NP-biased verbs) or by verbs that are generally used most frequently with $\mathrm{S}$ complements (S-biased verbs). Table 1 displays sample stimuli used in the experiment.

Verb guidance theories, generally, and constraint satisfaction, specifically, predict that readers interpret ambiguous NPs following NP-biased verbs as NP complements and ambiguous NPs following S-biased verbs as subject NPs of S complements. The difference in reading time between ambiguous and unambiguous $\mathrm{S}$ complement continuations is predicted to be larger for NP-biased than for S-biased verb conditions. Reading time on sentences containing ambiguous NP complements is predicted to be longer for S-biased than NP-biased verbs. In contrast, the garden path model predicts that readers will initially interpret ambiguous NPs as NP complements, as NP complements are syntactically less complex than S complements. The difference in reading time between ambiguous and unambiguous $\mathrm{S}$ complement continuations is predicted to be significant for both NP-biased and for S-biased verb conditions. Reading time on sentences containing ambiguous NP complements is predicted to be faster than on sentences containing ambiguous $\mathrm{S}$ complements, for both NP-biased and S-biased verb conditions.

The present experiment provides the most thorough test, thus far, of the effect of verb information on the resolution of the NP/S complement ambiguity and improves upon previous investigations in three major ways. First, it improves upon the design used in a number of important investigations (Ferreira \& Henderson, 1990; Garnsey, Pearlmutter, Myers, \& Lotocky, 1997; Holmes et al., 1989; Trueswell, Tanenhaus, \& Kello, 1993), as these experiments compared reading time on ambiguous and unambiguous $\mathrm{S}$ complements, but did not test sentences containing ambiguous NP complements. Second, the present study improves upon a prior investigation that did test the effect of verb information on how readers resolved sentences containing the ambiguous NP and S complements as well as unambiguous S complements (Kennedy et al., 1989). This prior study used materials in which the disambiguating regions of ambiguous NP and S complements were not well matched on how quickly readers could diagnose the structure of the NP continuation. The disambiguating region of $\mathrm{S}$ complements, as is shown in $2 \mathrm{a}$, was matched with the final prepositional phrase in the NP complement, as is shown in $2 b$.

(2) a. The workers considered /the last offer from the management /was an insult.

b. The workers considered /the last offer from the management /of the factory.

Readers could determine that the NP was an NP complement only when the end of the sentence was reached, as signaled by the period. Thus, disambiguation occurred later for NP than for S complements. In the present investigation, since NP complement continuations contained subordinate conjunctions that unambiguously signaled the closure of the NP, the readers received disambiguating information in a comparable manner for both NP and S complement continuations. Last, efforts were also made during the construction of materials used in the present study to ensure that ambiguous NPs were comparable in terms of plausibility as NP complements for both NPand S-biased verbs. In previous studies (e.g., Ferreira \& Henderson, 1990, and Trueswell et al., 1993), verb bias and plausibility of the NP complement analysis may have been confounded. One of these investigations (Trueswell et al., 1993) reported results indicating that verb information guided ambiguity resolution. However, plausibility ratings obtained for the materials used by Trueswell et al. indicated that the plausibility of an NP complement was inadvertently confounded with verb bias. Ambiguous NPs were rated as 6.35 as NP complements of NP-biased verbs, but only as 2.81 as NP complements of S-biased verbs. Recent investigations have shown that readers uti- 
lize information about plausibility as well as about verb information during ambiguity resolution (Garnsey et al., 1997). Consequently, the results of Trueswell et al. should be viewed as reflecting the effects of plausibility differences across conditions as well as differences in verb information.

The present experiment also tested the effect of ambiguity length on the resolution of the ambiguous NPs. A number of prior investigations have shown that longer ambiguous regions are associated with larger reading time differences between ambiguous versus unambiguous sentences (Ferreira \& Henderson, 1991; Frazier \& Rayner, 1982; Kennedy \& Murray, 1984). These results could be interpreted as indicating that readers have a more difficult time revising an initial analysis when they have maintained that analysis for a longer period of time. It was reasoned that if readers use verb information to construct initial analyses of ambiguous NPs, as predicted by constraint satisfaction, the effect of NP length would influence the processing of those sentences containing NP-biased verbs more so than those containing S-biased verbs, as reanalysis is predicted to occur in the former, rather than in the latter conditions. In the present experiment, ambiguous NPs were either short, composed of a determiner and a noun, or long, composed of a determiner, noun, and prepositional phrase.

The present experiment also explored the proposal that during the comprehension of sentences containing $\mathrm{S}$ complements, readers are influenced by a second type of verb information. Trueswell et al. (1993) provided evidence that readers use information about the frequency with which specific S-biased verbs are used with a complementizer in $\mathrm{S}$ complements. Trueswell et al. referred to this particular type of verb usage frequency as that-preference. The results suggested that when a sentence contains an S-biased verb, constructing an $\mathrm{S}$ complement when a complementizer is absent is more difficult when the verb is one that is generally used with a complementizer (i.e., a verb having a high "that" preference) than when the verb is one that is generally used without a complementizer (i.e., having a low "that" preference). For example, the verb concluded generally occurs with an overt complementizer when used with an S complement, as shown in 3a and 3b, and the verb assumed generally does not, as shown in $3 \mathrm{c}$ and $3 \mathrm{~d}$. According to Trueswell et al.'s proposal, the difference in processing difficulty between $3 \mathrm{a}$ and $3 \mathrm{~b}$ would be greater than the difference in processing difficulty between $3 \mathrm{c}$ and $3 \mathrm{~d}$. The processing difficulty would occur as soon as the reader begins constructing the $\mathrm{S}$ complement, presumably during and following the processing of the ambiguous NP.

(3) a. Mary concluded the answer was incorrect.

b. Mary concluded that the answer was incorrect.

c. Mary assumed the answer was incorrect. d. Mary assumed that the

unambiguous answer was incorrect.

The correlational analyses that were conducted to explore the extent to which readers were influenced by "that"preference information were conducted using two methods. The initial method used was the one used by Trueswell et al. This method involved correlating item-byitem mean reading time differences (ambiguous vs. unambiguous) averaged across participants with the "that"preference for the specific S-biased verb used in that item. Lorch and Myers (1990) argued that this method is not the most appropriate method for repeated measures designs, since it is susceptible to the occurrence of Type I errors. Following the recommendations of Lorch and Myers, the second method that was used to analyze the data described in this paper is a more appropriate method for repeated measures designs. This method involved computing regression equations for each participant using "that"-preference as a predictor variable and reading time in ambiguous and unambiguous $\mathrm{S}$ complements as the predicted variables. The mean slopes of these regression equations were compared. The use of both statistical methods ensured that the role of "that"-preference in sentence comprehension was investigated in the most thorough manner.

\section{METHOD}

\section{Materials and Design}

Forty-eight experimental sentences were constructed. Twentyfour S-biased and 27 NP-biased verbs were selected from two sources: Trueswell et al. (1993) and Kennison (1999). The NP-biased verbs occurred on average $66 \%$ of the time with NP complements $(S D=25$, range $=7-100)$ and $10 \%$ of the time with $S$ complements $(S D=12 \%$, range $=0-43)$. The S-biased verbs occurred on average $59 \%$ of the time with $S$ complements $(S D=15$, range $=29-93)$ and $24 \%$ of the time with NP complements $(S D=12$, range $=$ 6-43). The average "that"-preference for S-biased verbs was $65 \%$ $(S D=29$, range $=0-100)$. Twelve versions of each experimental sentence were constructed. Sentences contained ambiguous NP complements, ambiguous (no-"that"), or unambiguous S complements ("that"). NP complement conditions were disambiguated by the presence of a conjunction (e.g., because, even though, although) following the ambiguous NP, which unambiguously signaled the closure of the NP and the beginning of a following subordinate clause. The disambiguating regions of NP and S complements were always three words, closely matched in length and printed frequency (as assessed by Francis \& Kučera, 1982) across NP and S complement conditions. Twelve counterbalancing lists were used so that each item was viewed equally often in each condition. A complete list of experimental materials has been posted at http:// psychology.okstate.edu/faculty/kennis/pbr.htm. Ninety filler sentences were used. Thirty-two of these were foils that contained ambiguous NPs continued as NP complements.

The plausibility of the ambiguous NPs as NP complements of the verbs in each item was assessed in a plausibility rating study. An additional group of 40 participants at the University of Illinois were presented with a list of 98 sentence fragments constructed from the materials used in the three experiments described in this paper. The fragments were of the form The noun verbed the noun. The participants were instructed to rate the plausibility of the fragment on a scale from 1 (least plausible) to 7 (most plausible). For NP-biased verb conditions, the mean was $5.98(S D=.79)$, and for S-biased verb conditions, the mean was $5.63(S D=.94)$. 
Table 2

Mean First Pass Reading Time and Mean Total Reading

Time (in Milliseconds) by Condition by Analysis Region

\begin{tabular}{|c|c|c|c|c|c|c|c|c|c|c|c|c|c|c|c|}
\hline \multirow[b]{3}{*}{ Verb } & \multirow[b]{3}{*}{ Sentence Type } & \multicolumn{14}{|c|}{ Analysis Region } \\
\hline & & \multicolumn{2}{|c|}{$\begin{array}{c}\mathrm{R} 1 \\
\text { Subject } \\
\end{array}$} & \multicolumn{2}{|c|}{$\begin{array}{c}\mathrm{R} 2 \\
\text { Verb } \\
\end{array}$} & \multicolumn{2}{|c|}{$\begin{array}{c}\text { R3 } \\
\text { Comp } \\
\end{array}$} & \multicolumn{2}{|c|}{$\begin{array}{l}\mathrm{R} 4 \\
\mathrm{NP} \\
\end{array}$} & \multicolumn{2}{|c|}{$\begin{array}{c}\text { R5 } \\
\text { Modifier } \\
\end{array}$} & \multicolumn{2}{|c|}{$\begin{array}{c}\text { R6 } \\
\text { Disambig }\end{array}$} & \multicolumn{2}{|c|}{$\begin{array}{c}\text { R7 } \\
\text { Post-Disamb } \\
\end{array}$} \\
\hline & & 1st Pass & Total & 1st Pass & Total & 1st Pass & Total & 1st Pass & Total & 1st Pass & Total & 1st Pass & Total & 1st Pass & Total \\
\hline \multicolumn{16}{|c|}{ Short Ambiguous Regions } \\
\hline \multirow[t]{2}{*}{ NP } & Ambiguous S & 1,277 & 1,432 & 357 & 490 & - & - & 490 & 737 & - & - & 890 & 1,258 & 1,585 & 1,684 \\
\hline & Unambiguous $\mathrm{S}$ & 1,314 & 1,418 & 365 & 445 & 275 & 304 & 464 & 669 & - & - & 811 & 994 & 1,537 & 1,737 \\
\hline \multirow{2}{*}{$\mathrm{S}$} & Unambiguous $\mathrm{S}$ & 1,260 & 1,373 & 380 & 441 & 256 & 272 & 465 & 658 & - & - & 786 & 973 & 1,612 & 1,726 \\
\hline & Ambiguous NP & 1,256 & 1,342 & 367 & 437 & - & - & 480 & 623 & - & - & 717 & 871 & 1,513 & 1,615 \\
\hline \multicolumn{16}{|c|}{ Long Ambiguous Regions } \\
\hline \multirow[t]{3}{*}{ NP } & Ambiguous S & 1,251 & 1,352 & 367 & 460 & - & - & 444 & 675 & 670 & 891 & 885 & 1,144 & 1,518 & 1,654 \\
\hline & Unambiguous $\mathrm{S}$ & 1,381 & 1,519 & 361 & 445 & 235 & 294 & 488 & 687 & 631 & 830 & 813 & 969 & 1,482 & 1,627 \\
\hline & Ambiguous NP & 1,272 & 1,381 & 372 & 436 & - & - & 449 & 584 & 697 & 797 & 669 & 737 & 1,391 & 1,501 \\
\hline
\end{tabular}

Note- $-R$, region; NP, noun phrase; S, sentence.

\section{Participants}

Thirty-six students at the University of Massachusetts, who were native speakers of American English and who had normal or corrected vision, participated for $\$ 5.00$ each.

\section{Procedure and Apparatus}

Eye movements were recorded by a Stanford Research Institute Dual Purkinje Eye tracker, which has a resolution of less than $10 \mathrm{~min}$ of arc. Viewing was binocular with eye position recorded from the right eye. The eye tracker was interfaced with an 80486 microcomputer, which controlled the presentation of the sentences. Sentences were presented using an 80-column VGA display, with approximately four characters per degree of visual angle. The experimental sentences were displayed on a maximum of three lines. For each item, the S- or NP-biased verb, ambiguous NP, and the disambiguating region occurred on the same line. The characters were in lowercase, except where capital characters were called for (at the beginning of sentences and proper names). The luminance from the monitor was adjusted to a comfortable brightness level for each participant and then held constant throughout the study, and the room was dark. Before each participant was tested, a bitebar was constructed, which minimized head movements during the experiment. The eye tracking system was then calibrated. This procedure required the participant to fixate nine markers sequentially (three markers on the top, middle, and bottom rows of the computer screen). The voltage was recorded and interpolated for the intervening columns and rows. Before each trial, the calibration was checked and repeated, if necessary. Comprehension questions appeared in the lower half of the computer screen. After incorrect responses, the word "ERROR" appeared on the computer screen. Fifty percent of sentences were followed by comprehension questions. A practice list of 12 items was initially presented, followed by a list of 48 experimental sentences intermixed with 90 fillers. The order of sentences was randomized for each participant. Each session lasted between 45-60 min.

\section{RESULTS}

Eye movement data was initially screened for false fixations, as recommended in Rayner, Sereno, Morris,
Schmauder, and Clifton (1989). The dataset was then trimmed. Individual fixations longer than $1,000 \mathrm{msec}$ or shorter than $50 \mathrm{msec}$ were eliminated. Two measures of reading time were analyzed: (1) first pass reading time, which is defined as the sum of all fixations in a region from when the eye first enters a region to when the eye first exits the region and (2) total reading time, which is defined as the sum of all fixations in a region. Sentences were divided into seven analysis regions: (1) the subject of the sentence; (2) the NP- or S-biased verb; (3) the complementizer; (4) the determiner-noun; (5) the modifier; (6) the three-word disambiguating region; and (7) the remainder of the sentence. These regions are displayed in Table 1 . Table 2 displays mean first pass and total reading time in milliseconds by condition for each analysis region. In all analyses of variances (ANOVAs) and comparisons, participants $\left(F_{1}\right)$ and items $\left(F_{2}\right)$ were treated as random variables, following the recommendations of Clark (1973). As there were no noteworthy results observed for Regions 1-3, the discussion will focus on Regions 4-7.

Contrary to the predictions of constraint satisfaction, verb type did not reliably influence how readers resolved ambiguous NPs. Interactions involving verb type and sentence type were not significant for any analysis region [Regions 5-7: $F \mathrm{~s}<1$ and Region 4: first pass, $F_{1}(2,70)=$ $2.27, p>.11 ; F_{2}(2,94)=1.51, p>.3$, and total, $\left.F_{\mathrm{S}}<1\right]$.

Patterns of reading time were consistent with predictions made by the garden path model, whose advocates claim that ambiguous NPs are initially analyzed as NP complements, the syntactically less complex analysis (versus the $\mathrm{S}$ complement). When readers encounter the disambiguating region (Region 6) in NP complement continuations, the initial NP complement analysis is supported and can be maintained; in ambiguous $\mathrm{S}$ comple- 
ment continuations, the initial NP complement analysis must be revised. Consequently, reading time was predicted to be shortest for NP complement continuations and longest for ambiguous $\mathrm{S}$ complement continuations. At the disambiguating region (Region 6), reading time was influenced significantly by sentence type [first pass: $F_{1}(2,70)=28.74, p<.001 ; F_{2}(2,94)=29.85, p<.001$, and total: $F_{1}(2,70)=35.90, p<.001 ; F_{2}(2,94)=54.50$, $p<.001]$. NP complement continuations were read more quickly than ambiguous $\mathrm{S}$ complement continuations [first pass: $F_{1}(1,35)=70.86, p<.001 ; F_{2}(1,47)=41.93$, $p<.001$, and total: $F_{1}(1,35)=74.97, p<.001 ; F_{2}(1,47)=$ $72.24, p<.001]$. Ambiguous $\mathrm{S}$ complement continuations were read more slowly than unambiguous $S$ complements [first pass: $F_{1}(1,35)=8.02, p<.008 ; F_{2}(1,47)=12.20$, $p<.002$, and total: $F_{1}(1,35)=15.29, p<.001 ; F_{2}(1,47)=$ $44.31, p<.001]$. Reading time on the disambiguating region was not significantly influenced by verb type or interactions involving verb type $\left(F_{\mathrm{s}}<1\right)$, or interactions involving sentence type [sentence type $\times$ NP length interaction; first pass: $F_{1}(2,70)=1.61, p>.20 ; F_{2}(2,94)=$ $1.67, p>.19$, and total: $F_{1}(2,70)=2.12, p>.29$; $F_{2}(2,94)=1.58, p>.21$, all others, $\left.F_{\mathrm{s}}<1\right]$.

A similar pattern of reading time was observed at the postdisambiguating region (Region 7). Reading time was significantly influenced by sentence type: [first pass: $F_{1}(2,70)=5.73, p<.006 ; F_{2}(2,94)=12.08, p<.001$, and total: $F_{1}(2,70)=8.76, p<.001 ; F_{2}(2,94)=16.90, p<$ $.001]$. NP complement continuations were read significantly more quickly than ambiguous $\mathrm{S}$ complement continuations: [first pass: $F_{1}(1,35)=13.79, p<.001$; $F_{2}(1,47)=16.05, p<.001$, and total: $F_{1}(1,35)=16.77$, $\left.p<.001 ; F_{2}(1,47)=20.64, p<.001\right]$. Reading time on ambiguous and unambiguous $\mathrm{S}$ complement continuations did not significantly vary $\left(F_{\mathrm{S}}<1\right)$. Reading time was not influenced by verb type [first pass: $F_{1}(1,35)=$ $2.41, p>.07 ; F_{2}(1,47)=2.35, p>.13$, and total: $F_{1}(1,35)$ $\left.=1.79, p>.18 ; F_{2}(1,47)=1.70, p>.19\right]$, NP length [first pass: $F_{1}(1,35)=2.31, p>.13 ; F_{2}(1,47)=3.56$, $p>.06$, and total: $F_{1}(1,35)=1.82, p>.18 ; F_{2}(1,47)=$ $2.46, p>.12]$, or interactions of factors $\left(F_{\mathrm{S}}<1\right)$.

First pass and total reading time on the two regions (Regions 4 and 5) preceding the disambiguation (Regions 6) show distinct patterns, both of which are consistent with the predictions of the garden path model. First pass reading time results indicate that in ambiguous NP and S complement conditions, readers maintained the initial NP complement analysis in Regions 4 and 5. First pass reading time on the determiner-noun region (Region 4) was not significantly influenced by any factor or any interaction of factors [sentence type: $F_{1}<1$; $F_{2}(2,70)=1.60, p>.20$, verb type: $F_{1}(1,35)=2.10, p>$ $.15 ; F_{2}<1$, NP length: $F_{1}(1,35)=1.54, p>.22 ; F_{2}<1$; NP length $\times$ sentence type: $F_{1}(2,70)=1.19, p>.31$; $F_{2}(2,94)=1.61, p>.20$, NP length $\times$ verb type: $F_{\mathrm{s}}<1$, verb type $\times$ sentence type: $F_{1}(2,70)=2.27, p>.11$; $F_{2}(2,94)=1.51, p>.22$, NP length $\times$ verb type $\times$ sentence type: $\left.F_{1}<1 ; F_{2}(2,94)=1.17, p>.31\right]$.
First pass reading time on the modifier region (Region 5) was longer for ambiguous NP and S complement conditions than for unambiguous $\mathrm{S}$ complement conditions $\left[F_{1}(1,35)=9.99, p<.003 ; F_{2}(1,47)=15.75, p<\right.$ .001 , and $F_{1}(1,35)=3.70, p<.07 ; F_{2}(1,47)=6.86, p<$ .02 , respectively], resulting in a significant effect of sentence type $\left[F_{1}(2,70)=4.22, p<.02 ; F_{2}(2,94)=6.69\right.$, $p<.002]$. Reading time for ambiguous NP and S complements did not differ significantly $\left[F_{1}<1 ; F_{2}(1,47)=\right.$ $1.13, p>.29]$. First pass reading time was longer for NPbiased verb conditions, resulting in a significant effect of verb type $\left[F_{1}(1,35)=5.08, p<.04 ; F_{2}(1,47)=5.68, p<\right.$ $.03]$. The verb type $\times$ sentence type interaction was not significant $\left(F_{\mathrm{s}}<1\right)$.

Total reading time results on Regions 4 and 5 indicate readers spent more time overall reading ambiguous $S$ complements than either ambiguous NP complements and unambiguous $\mathrm{S}$ complements, since more rereading occurred in ambiguous $\mathrm{S}$ complements once the disambiguation was encountered. Total reading time was longer for ambiguous $\mathrm{S}$ complements than for unambiguous $\mathrm{S}$ complements $\left[F_{1}(1,35)=3.95, p<.06 ; F_{2}(1,47)=5.70\right.$, $p<.03]$, and for ambiguous NP complements $\left[F_{1}(1,35)=\right.$ $\left.12.60, p<.002 ; F_{2}(1,47)=9.51, p<.004\right]$. The main effect of sentence type was significant $\left[F_{1}(2,70)=12.49\right.$, $\left.p<.001 ; F_{2}(2,94)=15.42, p<.001\right]$. Total reading time was not significantly influenced by verb type ( $F_{\mathrm{S}}<$ 1) or by interactions of factors [NP length $\times$ sentence type: $F_{1}<1 ; F_{2}(2,94)=1.07, p>.34$, NP length $\times$ verb type: $F_{1}(2,70)=1.02, p>.32 ; F_{2}(2,94)=1.48, p>.23$, verb type $\times$ sentence type: $F_{\mathrm{S}}<1$; NP length $\times$ verb type $\times$ sentence type: $F_{\mathrm{s}}<1$ ]. There was a significant main effect of NP length, resulting because total reading time was longer for long than for short NP conditions $\left[F_{1}(1,35)\right.$ $\left.=4.17, p<.05 ; F_{2}(1,47)=3.63, p<.07\right]$.

Total reading time on the modifier region (Region 5) was longer for ambiguous $\mathrm{S}$ complements than for ambiguous NP and unambiguous $\mathrm{S}$ complements $\left[F_{1}(1,35)=\right.$ $3.65, p<.07 ; F_{2}(1,47)=4.72, p<.04$, and, $F_{1}(1,35)=$ $5.87, p<.03 ; F_{2}(1,47)=4.70, p<.04$, respectively], resulting in a significant main effect of sentence type $\left[F_{1}(2,70)=3.14, p<.05 ; F_{2}(2,94)=3.46, p<.04\right]$. Total reading time on Region 5 was not significantly influenced by verb type $\left[F_{1}(1,35)=2.75, p>.10 ; F_{2}(1,47)=\right.$ $1.73, p>.19]$, or by an interaction of verb type and sentence type $\left(F_{\mathrm{S}}<1\right)$.

In order to explore the extent to which readers used "that"-preference information during the comprehension of sentences, multiple statistical analyses were conducted. The first method was the one used by Trueswell et al. (1993), which involved regressing differences in mean reading time per item averaged across participants. Two predictor variables were used: "that"-preference and transformed "that"-preference $[\log (p / 1-p)]$, which was desirable since the percentage range for "that"-preference was bounded. The second method involved computing for each participant regression equations between reading time differences for ambiguous and unambiguous $\mathrm{S}$ 
complements using "that"-preference and transformed "that"-preference $[\log (p / 1-p)]$ as predictor variables and later testing the mean slopes of the regression equations. This is a statistically more appropriate method for repeated measures designs and one less susceptible to Type I errors (Lorch \& Myers, 1990). The mean "that"-preference for the S-biased verbs included in these analyses was $65 \%(S D=$ $26 \%$, range $=0-100$ ). The results of these analyses indicated that reading time differences observed at the disambiguating region for S-biased verb conditions between ambiguous and unambiguous $\mathrm{S}$ complements were not consistently related to S-biased verbs' "that"-preference (Method 1, first pass: $r=-.07, p=.33$; Method 1, total time: $r=.06, p=.35$; Method 2, first pass: $r=.13, p=$ .20 ; Method 2, total time: $r=.17, p=.16$ ) or transformed "that"-preference (Method 1, first pass: $r=-.05, p=.37$; Method 1, total time: $r=-.10, p=.26$; Method 2, first pass: $r=.22, p=.09$; Method 2, total time: $r=.26, p=$ .07). In light of these results, the previously proposed role of "that"-preference in the resolution of ambiguous NPs must be reevaluated (see also Kennison, 1995).

\section{GENERAL DISCUSSION}

An eye tracking experiment was conducted to investigate the extent to which readers are influenced by verb information during the resolution of ambiguous NPs. In the experiment, reading time was measured for sentences containing either unambiguous $\mathrm{S}$ complements or ambiguous NPs continued as NP complements or S complements, preceded by NP- or S-biased verbs. The results of the present experiment indicate that readers were not influenced by verb information. Regardless of the type of verb preceding the ambiguous NP, readers took longer to read $\mathrm{S}$ complement continuations than NP complement continuations, and readers took longer to read ambiguous $\mathrm{S}$ complements than unambiguous $\mathrm{S}$ complements. These results provide evidence against theories of sentence processing in which verb information is claimed to play a guiding role in syntactic ambiguity resolution. Furthermore, no evidence was found to support the claim (Trueswell et al., 1993) that readers are influenced by the frequency with which specific S-biased verbs are used with the complementizer that. Such a result would be consistent with the view of sentence processing held by proponents of constraint satisfaction. The results are consistent with the garden path model of sentence processing, which claims that readers construct the first analysis available, which is the least syntactically complex analysis, in this case, the NP complement.

\section{REFERENCES}

Clark, H. H. (1973). The language-as-fixed-effect fallacy: A critique of language statistics in psychological research. Journal of Verbal Learning \& Verbal Behavior, 12, 335-359.

Clifton, C., Jr., Frazier, L., \& Connine, C. (1984). Lexical expecta- tions in sentence comprehension. Journal of Verbal Learning \& Verbal Behavior, 23, 696-708.

Ferreira, F., \& Henderson, J. (1990). Use of verb information during syntactic parsing: Evidence from eye tracking and word by word selfpaced reading. Journal of Experimental Psychology: Learning, Memory, \& Cognition, 16, 555-568.

Ferreira, F., \& Henderson, J. (1991). Recovery from misanalyses of garden-path sentences. Journal of Memory \& Language, 30, 725745.

Ford, M., Bresnan, J., \& Kaplan, R. M. (1982). A competence-based theory of syntactic closure. In J. Bresnan (Ed.), The mental representation of grammatical relations (pp. 727-796). Cambridge, MA: MIT Press.

Francis, W. N., \& KuČera, H. (1982). Frequency analysis of English usage: Lexicon and grammar. Boston: Houghton Mifflin.

FrAZIER, L. (1978). On comprehending sentences: Syntactic parsing strategies. Unpublished doctoral dissertation, University of Connecticut.

Frazier,L., \& Fodor, J. D. (1978). The sausage machine: A new twostage parsing model. Cognition, 6, 1-34.

FrAZIER, L., \& RAYNER, K. (1982). Making and correcting errors during sentence comprehension: Eye movements in the analysis of structurally ambiguous sentences. Cognitive Psychology, 14, 178210 .

Garnsey, S. M., Pearlmutter, N. J., Myers, E., \& Lotocky, M. (1997). The contributions of verb bias and plausibility to the comprehension of temporarily ambiguous sentences. Journal of Memory \& Language, 37, 58-93.

Holmes, V. M., Kennedy, A., \& Murray, W. S. (1987). Syntactic structure and the garden path. Quarterly Journal of Experimental Psychology, 39A, 277-294.

Holmes, V. M., Stowe, L. A., \& Cupples, L. (1989). Lexical expectations in parsing complement verb sentences. Journal of Memory \& Language, 28, 668-689.

Kennedy, A., \& MurRAY, W. S. (1984). Inspection times for words in syntactically ambiguous sentences under three presentation conditions. Journal of Experimental Psychology: Human Perception \& Performance, 10, 833-847.

Kennedy, A., Murray, W. S., Jennings, F., \& Reid, C. (1989). Parsing complements: Comments on the generality of the principle of minimal attachment. Language \& Cognitive Processes, 4, SI51SI76.

KenNisOn, S. M. (1995). The role of verb-specific lexical information in syntactic ambiguity resolution. Unpublished doctoral dissertation, University of Massachusetts, Amherst.

Kennison, S. M. (1999). American English usage frequencies for noun phrase and S complement-taking verbs. Journal of Psycholinguistic Research, 28, 165-177.

LoRCH, R, \& MEYERS, J. (1990). Regression analysis of repeated measures data in cognitive research. Journal of Experimental Psychology: Learning, Memory, \& Cognition, 16, 149-157.

MacDonald, M. (1994). Probabilistic constraints and syntactic ambiguity resolution. Language \& Cognitive Processes, 9, 157-201.

MacDonald, M., Pearlmutter, N. J., \& Seidenberg, M. S. (1994a). The lexical nature of syntactic ambiguity resolution. Psychological Review, 101, 676-703.

MacDonald, M., Pearlmutter, N. J., \& Seidenberg, M. S. (1994b). Syntactic ambiguity resolution as lexical ambiguity resolution. In C. Clifton, L. Frazier, \& K. Rayner (Eds.), Perspectives on sentence processing (pp. 123-154). Hillsdale, NJ: Erlbaum.

Mitchell, D. C. (1987). Lexical guidance in human parsing: Locus and processing characteristics. In M. Coltheart (Ed.), Attention and performance XII (pp. 601-618). Hillsdale, NJ: Erlbaum.

Mitchell, D. C. (1989). Verb guidance and other lexical effects in parsing. Language \& Cognitive Processes, 4, 123-154.

Mitchell, D. C., \& Holmes, V. M. (1985). The role of specific information about the verb in parsing sentences with local structural ambiguity. Journal of Memory \& Language, 24, 542-559.

Rayner, K., Sereno, S., Morris, R., Schmauder, R., \& Clifton, C., Jr. 
(1989). Eye movements and on-line language comprehension processes. Language \& Cognitive Processes, 4, 21-50.

Tanenhaus, M. K., \& Carlson, G. N. (1989). Lexical structure and language comprehension. In W. Marslen-Wilson (Ed.), Lexical representation and process (pp. 529-561). Cambridge, MA: MIT Press.

Trueswell, J., \& Tanenhaus, M. K. (1994). Toward a lexicalist framework for constraint-based syntactic ambiguity resolution. In C. Clifton, L. Frazier, \& K. Rayner (Eds.), Perspectives on sentence processing (pp. 155-179). Hillsdale, NJ: Erlbaum.
Trueswell, J. C., Tanenhaus, M. K., \& Kello, C. (1993). Verbspecific constraints in sentence processing: Separating effects of lexical preference from garden-paths. Journal of Experimental Psychology: Learning, Memory, \& Cognition, 19, 528-553.

(Manuscript received June 23, 1999; revision accepted for publication March 1, 2000.) 